\title{
Nanoporous Carbon Prepared with MOF-5 as a Template and Activated using KOH for Hydrogen Storage
}

\author{
Ratna Ediati $^{*}$, Tri Ana Mulyati ${ }^{2}$, Amirul Mukminin $^{3}$, Dety Oktavia Sulistiono $^{1}$, \\ Naimatul Khoiroh ${ }^{1}$, Hamzah Fansuri ${ }^{1}$, Didik Prasetyoko ${ }^{1}$ \\ ${ }^{1}$ Department of Chemistry, Faculty of Science and Data Analytics, Institut Teknologi Sepuluh Nopember \\ Jl. Arif Rahman Hakim, Kampus ITS Keputih-Sukolilo, Surabaya 60111, Indonesia \\ ${ }^{2}$ Institute of Health Sciences Bhakti Wiyata Kediri \\ Jl. KH Wachid Hasyim No 65, Bandar Lor, Kota Kediri 64114, Indonesia \\ ${ }^{3}$ Oil and Gas College of Balikpapan, Indonesia \\ Jalan Wiluyo Puspoyudo No 3676124 Kalimantan Timur, Indonesia Kalimantan Timur, Indonesia \\ *Corresponding Author. E-mail: rediati@chem.its.ac.id; ratna.ediati@gmail.com
}

Received: December 2019; Revision: December 2019; Accepted: April 2020; Available online: May 2020

\begin{abstract}
A series of nanoporous carbon was prepared with MOF-5 as a template and furfuryl alcohol as an additional carbon source by carbonation at temperatures of $550{ }^{\circ} \mathrm{C}$ and $900{ }^{\circ} \mathrm{C}$, respectively, with and without activation using KOH. XRD patterns of the obtained carbons before and after the activation process showed characteristic peaks at the same $2 \theta$ values, which corresponded to the XRD pattern of a $\mathrm{ZnO}$. The Surface morphology of the MOF-5 templated carbon with a carbonation temperature of $550^{\circ} \mathrm{C}$ was in the form of a cube. In contrast, the one carbonated at $900{ }^{\circ} \mathrm{C}$ had a cubic and circular morphology. The $\mathrm{N}_{2}$ adsorption-desorption isothermal showed that MOF-5 templated carbon had a larger specific surface area, pore diameter, and pore volume than those of the original MOF-5. Activation of the MOF-5 templated carbon using KOH resulted in a decrease in surface area and pore volume. All the materials were measured for their hydrogen adsorption at room temperature and atmospheric pressure using a gravimetric method.
\end{abstract}

Keywords: MOF-5 templated carbon, adsorption, hydrogen storage, gravimetry.

DOI: $10.15408 / j k v . v 6 i 1.13621$

\section{INTRODUCTION}

The use of hydrogen as an ideal energy source for transportation systems and various energy generators has received great attention because hydrogen can be produced from renewable sources and environmentally friendly combustion products. As a fuel, hydrogen contains more energy per kilogram than gasoline or natural gas, but its use has not been widespread due to its low density and difficulty in storing. The effective technology for storing hydrogen with good storage capacity is one of the most important factors in the development of hydrogen fuel science for transportation. Various methods have been developed to store hydrogen, namely liquefaction, compressed hydrogen and storage in solid material. The latter is very effective because it does not require high energy (Hu and Zhang, 2010). Large specific surface area and regular pore size play an important role in gas storage with solid material. One material with these properties is the Metal-Organic Framework (MOF), a porous material which comprises of metal ions being linked with organic ligands, forms a 3D structure (Greer et al., 2016). MOF has high crystallinity and porosity, as well as large surface area, hence making it suitable to be used as a hydrogen storage material. One type of MOF that has been reported being used as hydrogen storage is MOF-5 (Ming et al., 2016).

MOF-5, also known as IRMOF-1, is a first porous material was developed by Yaghi et al., 1999, which consists of transition metal of $\mathrm{Zn}$ in an octahedral lattice $\left[\mathrm{Zn}_{4} \mathrm{O}\right]^{6+}$ that coordinates with the organic benzene-1,4-dicarboxylic acid ligands to form a cube-shaped $\mathrm{Zn}_{4} \mathrm{O}$ porous framework. Li et al., 
2015 reported that MOF-5 could adsorb $\mathrm{H}_{2}$ by $3.6 \mathrm{wt} \%$ at $77 \mathrm{~K}$ and $1.74 \mathrm{MPa}$. Other studies also reported that MOF-5 was able to adsorb hydrogen at greater than $5 \mathrm{wt} \%$ at $77 \mathrm{~K}$ and a pressure of $4 \mathrm{MPa}$ (Juan et al., 2010). On the other hand, however, MOF has some drawbacks, including that it is not water, steam and temperatures resistant. Therefore, it cannot be used in the industrial-scale application process due to its low thermal stability (Liu et al., 2016; Ata-ur-Rehman et al., 2018).

In view of the existing problems, MOF (MOF templated carbon) composite research has been conducted to form a micro-meso-hierarchy pore that can overcome the diffusion problem of molecule adsorption and increase the specific surface area to improve its performance in hydrogen storage applications (Jiang et al., 2011; Ming et al., 2016; Yap et al., 2017). MOF-5 template carbon has some advantages, these are being able to serve as a carbon precursor, produces pores as MOF-5, in addition to increase surface area, pore volume, and hydrogen storage capacity (Hu et al., 2010; Yang et al., 2012; Segakweng et al., 2016; Liu et al., 2016). Hu et al., (2010) reported that the use of MOF-5 as a carbon template could increase the surface area to $1812 \mathrm{~m}^{2} / \mathrm{gr}$ (Hu et al., 2010). Porous carbon with hierarchically pore structure, high specific surface area, high ultra-microporosity and high hydrogen storage capacity was successfully prepared by Yang et al., 2012 using IRMOF-1 as template without additional carbon source. The resultant carbon material retained the cubic morphology of the IRMOF-1, even after high-temperature carbonation, as indicated by SEM image (Yang et al., 2012). Direct carbonation of MOF-5 at various calcination temperature was reported by Segakweng et al., 2016 in which the obtained carbon materials showed higher surface area, higher pore volume and enhanced hydrogen storage capacity than that of the original MOF-5 (Segakweng et al., 2016). Another advantage of MOF-5 templated carbon as a hydrogen storage is the existence of $\mathrm{ZnO}$ on the carbon. The $\mathrm{Zn}$ metal clusters on MOF-5 has a higher affinity to adsorb hydrogen molecules, hence increasing its hydrogen storage capacity (Hou et al., 2016). Based on the research performed by Lestari et al., 2018 , it was suggested that porous carbon with MOF-5 template carbonated at $550{ }^{\circ} \mathrm{C}$ produced a $\mathrm{ZnO}$. When the process is performed at $900{ }^{\circ} \mathrm{C}$, however, only carbon is formed. However, no research has been done yet in regards to comparing $\mathrm{ZnO} @ \mathrm{C}$ and $\mathrm{C}$ as a hydrogen storage materials.

Besides from the advantages of MOF-5 as the aforementioned porous carbon template, MOF-5 templated porous carbon also has its weaknesses, amongst which is it still produces a varied pore size (Khan et al., 2017; Srinivas et al., 2014). Srinivas et al., 2014 reported that MOF-5 templated porous carbon generated mostly micropores, as well as meso- and macropores as a result from defects in the individual crystals (Srinivas et al., 2014). Carbon with different pore regions from micro to macro size was obtained by carbonation of MOF-5/activated carbon composite at $850{ }^{\circ} \mathrm{C}$ (Khan et al., 2017). Ma et al., (2018) also reported that micropore structure of carbons obtained using MOF-5 as a template with urea as an additional carbon source was slightly changed with the increase in carbonation temperatures in the range of $600-900{ }^{\circ} \mathrm{C}$. Carbon with highest specific surface area was achieved at a carbonation temperature of $900{ }^{\circ} \mathrm{C}$ (Ma et al., 2018).

Such hierarchical pores problems can be dealt with by utilization of additional carbon source and chemical activation of the obtained carbon. Almasoudi and Mokaya (2012) reported that ZIF-8 templated carbon underwent an increase in surface area, pore volume, and hydrogen storage capacity when furfuryl alcohol was used as additional carbon source, followed by chemical activation with $\mathrm{KOH}$. The activated ZIF-templated carbon retained significant microporosity as the activation process mainly enhanced the existing porosity rather than creating new larger pores (Almasoudi and Mokaya, 2012). Furthermore, Lee and Park (2012a) reported that activation of multi-walled carbon nanotubes using $\mathrm{KOH}$ resulted in the narrow of microporosity distribution and the increase in specific surface area of the obtained activated multi-walled carbon nanotubes, which led to an increase in the hydrogen storage capacity (Lee and Park, 2012a). In addition to activation with bases, the activation of carbon micropores with acids was also reported to enhance hydrogen storage capacity. Lee and Park (2012b) synthesized zeolite-casted microporous carbon using a replica casting method, followed by activation of the obtained carbon using $\mathrm{H}_{3} \mathrm{PO}_{4}$ and $\mathrm{KOH}$. The BET surface area and micropore volume of the zeolite-casted carbon were significantly higher than that of zeolite template. The acid treatment resulted in 
the increase in the hydrogen storage capacity of the resultant carbon, which was attributed to charge-induced dipole interaction at specific sites on the acid-treated carbon surfaces, resulting from the formation of oxygen groups (Lee and Park, 2012b). On the contrary, however, $\mathrm{Hu}$ et al., (2010) reported that activation of MOF-5 templated carbon using $\mathrm{KOH}$ decreased the surface area and pore volume, which was due to the destruction of porosity (Hu et al., 2010).

In our previous research, MOF-5 was successfully synthesized using a solvothermal method at various temperatures and times (Mulyati et al., 2015). Furthermore, a series of mesoporous carbons was also successfully prepared using mesoporous ZSM-5 as a hard template with sucrose as carbon source at a carbonization temperature of $900{ }^{\circ} \mathrm{C}$. Impregnation of nickel on the obtained mesoporous carbon resulted in the decrease in the specific surface area of the $\mathrm{Ni}$-impregnated carbons. The more the $\mathrm{Ni}$ loaded on the mesoporous carbon, the higher the hydrogen adsorption capacity of the obtained Ni-carbon was observed (Ediati et al., 2017). However, preparation of nanoporous carbons using hard templates experienced some drawbacks, such as the need of removal of the hard templates. In this study, nanoporous carbons were prepared using MOF-5 as template with furfuryl alcohol as additional carbon source, followed by activation using $\mathrm{KOH}$. All the obtained materials were then measured for their hydrogen storage capacity.

\section{MATERIALS AND METHODS Materials}

The materials used in this research were zinc nitrate hexahydrate $\left(\mathrm{Zn}\left(\mathrm{NO}_{3}\right)_{2} .6 \mathrm{H}_{2} \mathrm{O}\right.$ Sigma-Aldrich,

Benzene-1,4-dicarboxylic acid $\left(\mathrm{H}_{2} \mathrm{BDC}\right.$ Sigma-Aldrich, $99.0 \%)$ N'N-dimethylformamide (DMF Merck, 99.8\%), chloroform $\left(\mathrm{CHCl}_{3}\right.$, Merck, 99.9\%), nitrogen gas, furfuryl alcohol (FA, Merck, 96.0\%), potassium hydroxide (KOH, Merck, 98\%), hydrochloric acid ( $\mathrm{HCl}$ Merck, 98\%) and demineralised water.

\section{Instrumentations}

The instrumentations used in this research were X-Ray diffractometer (XRD-JEOL), FTIR spectrophotometer (8400S Shimadzu), Scanning Electron Microscope (SEM-Zeiss, EVO MA10), Surface Area Analyzer (Micromeritic Quantachrome), and adsorption-desorption hydrogen.

\section{Synthesis of MOF-5}

The method for synthesis of MOF-5 has been published elsewhere (Mulyati et al., 2015). $1.08 \mathrm{~g}$ of $\mathrm{Zn}\left(\mathrm{NO}_{3}\right)_{2} \cdot 6 \mathrm{H}_{2} \mathrm{O}(6.1 \mathrm{mmol})$ and 0.198 $\mathrm{g}$ of $\mathrm{H}_{2} \mathrm{BDC}$ ( $\left.2.0 \mathrm{mmol}\right)$ were dissolved in 30 $\mathrm{mL}$ of DMF and then stirred for 30 minutes. The solution formed was then heated at $140{ }^{\circ} \mathrm{C}$ for 24 hours. The obtained solid was separated and dried in a vacuum at $60-70{ }^{\circ} \mathrm{C}$ for 2 hours and was then labeled as MOF-5.

\section{Synthesis of MOF-5 Templated Carbon}

$1 \mathrm{~g}$ of MOF-5 was immersed in $5 \mathrm{~mL}$ of FA. The mixture was stirred for 40 minutes and left stationary for overnight in order for the whole FA to absorb into the MOF-5 pores. The obtained solid was filtered and washed with ethanol. The carbonations process was initiated by heating the solid in a stream of nitrogen at 80 ${ }^{\circ} \mathrm{C}$ for 4 hours, and then the temperature was increased to $150{ }^{\circ} \mathrm{C}$ for 4 hours. Subsequently, the materials were calcinated at different temperatures of 550 to $900^{\circ} \mathrm{C}$ under the nitrogen atmosphere in order to complete the carbonization process for 4 hours. The carbonated solids at $550{ }^{\circ} \mathrm{C}$ was then labeled with C-MOF-5-550, whereas the solids carbonated at $900{ }^{\circ} \mathrm{C}$ was then labeled with C-MOF-5-900.

\section{Activating MOF-5 Templated Carbon}

$0.2 \mathrm{~g}$ of MOF-5 templated porous carbon was mixed with $0.8 \mathrm{~g}$ of $\mathrm{KOH} 1 \mathrm{M}$ solution (ratio of MOF: $\mathrm{KOH}$ was 1:4) and stirred at room temperature for 24 hours. The carbons were washed with demineralized water several times until the washing water reached a $\mathrm{pH}$ neutral, and dried at $100^{\circ} \mathrm{C}$ for 24 hours. The activated carbons of C-MOF-5-550 and C-MOF-5-900 were labeled with AC-MOF-5-550 and AC-MOF-5-900, respectively.

\section{RESULTS AND DISCUSSIONS Structures Analysis}

The analysis on the solid structure was undertaken by comparing the XRD patterns and the FTIR spectra of the MOF-5 templated carbon before and after activation process, as are displayed in Figure 1, and Figure 2, respectively.

Figure 1 shows that an amorphous diffraction is present at a peak of $5-30^{\circ}$, which is a characteristic of carbon materials. The $\mathrm{ZnO}$ 
characteristic peaks are seen at $31.81^{\circ} ; 34.49^{\circ}$; $36.21^{\circ}$, all with high intensity, and at $47.48^{\circ}$ with medium intensity. This suggests that the MOF-5 frameworks have been decomposed into $\mathrm{ZnO}$ and carbon material, as referred to (Jiang et al., 2011). According to Liu et al., 2010, Zn metal boils at $908{ }^{\circ} \mathrm{C}$, hence at carbonation temperature used at less than $908{ }^{\circ} \mathrm{C}$ result in a $\mathrm{ZnO}$ phase on MOF-5 templated porous carbon. As the carbonation temperature increases, the $\mathrm{ZnO}$ characteristic peak intensity is decreased. This shows that there were more $\mathrm{ZnO}$ phase in C-MOF-5-550 when compared to

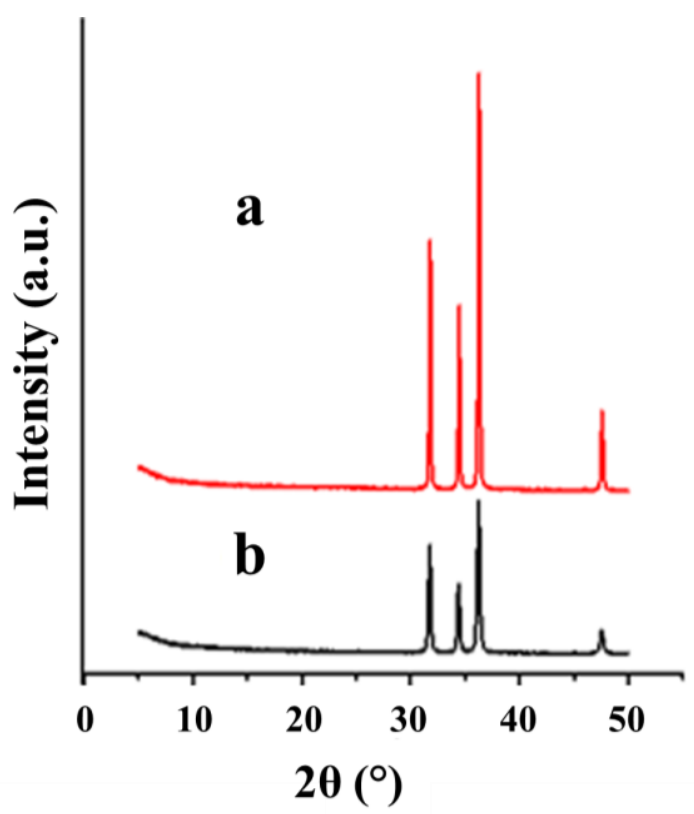

C-MOF-5-900. Furthermore, Figure 1 also shows that the XRD patterns for MOF-5 templated carbon before and after activation process have the same carbon XRD pattern. The similarity of the diffraction pattern can indicate that the carbon with MOF-5 template before and after activation has the same structure, namely carbon and $\mathrm{ZnO}$, as shown by the research undertaken by Sevilla et al., 2011. On the other hand, the intensity of the $\mathrm{ZnO}$ characteristic peak has diminished after being activated with $\mathrm{KOH}$, which indicates that the porous carbon has been successfully activated with $\mathrm{KOH}$.

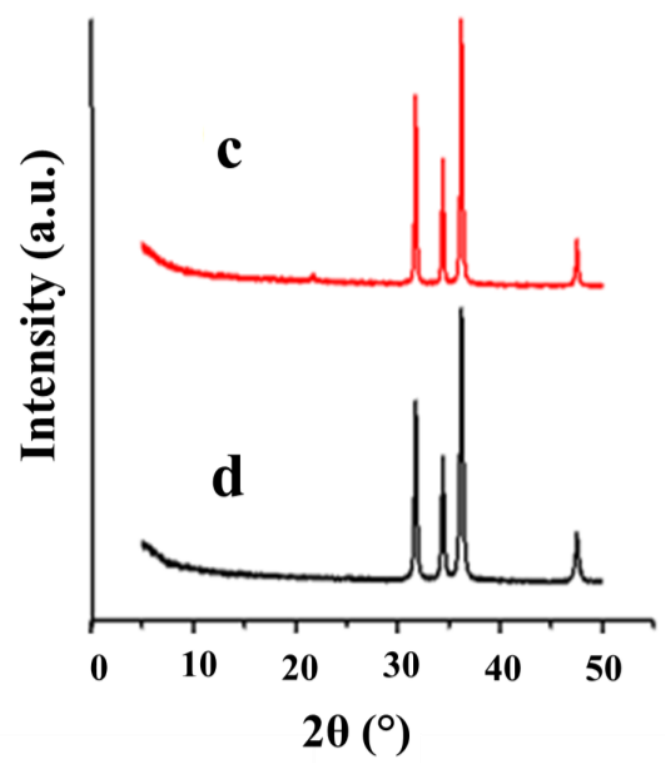

Figure 1. The diffractogram patterns of MOF-5 templated carbons, (a) C-MOF-5-550, (b) C-MOF-5-900, (c) AC-MOF-5-550 and (d) AC-MOF-5-900.
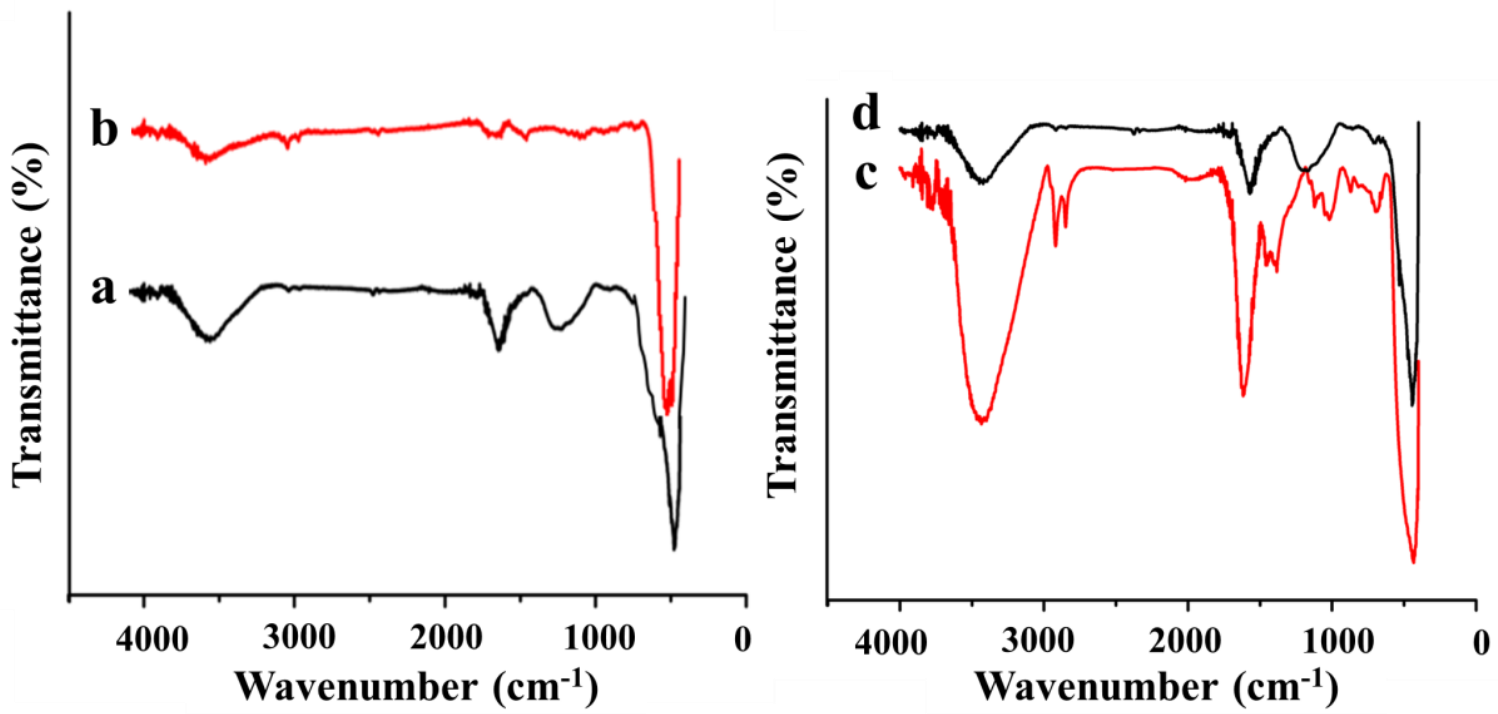

Figure 2. The FTIR spectra of MOF-5 templated carbons, (a) C-MOF-5-550, (b) C-MOF-5-900, (c) AC-MOF-5-550 and (d) AC-MOF-5-900. 
Figure 2a shows that in the C-MOF-5-550 spectra, there is a peak in the area of $3500 \mathrm{~cm}^{-1}$ with moderate intensity indicating the presence of $\mathrm{O}-\mathrm{H}$ stretching vibrations due to physically absorbed water. Moreover, there are still characteristic peaks of MOF-5 in the area of $1579 \mathrm{~cm}^{-1}$ and $1213 \mathrm{~cm}^{-1}$ which show dicarboxylic bridges, with low intensity. This may be caused by relatively low carbonation temperature, hence during which carbonation occurs, the dicarboxylate bridge did not disconnect perfectly. On C-MOF-5-900 (Figure 2b), a peak characteristic MOF-5 dicarboxylate bridge can also be seen, however, it has been shifted towards $\mathrm{cm}^{-1}$ and $1383 \mathrm{~cm}^{-1}$ with very low intensity. This may be caused by the relatively high carbonation temperature, hence when being carbonated, the decarboxylate bridge disconnected more perfectly. All the spectra for MOF-5 templated carbon showed a peak at $450 \mathrm{~cm}^{-1}$ with high intensity, which suggests a $\mathrm{Zn}-\mathrm{O}$ stretching vibration due to the presence of $\mathrm{Zn}$ oxide.

Figures $2 \mathrm{c}$ and $2 \mathrm{~d}$ demonstrate that FTIR spectra for MOF-5 templated carbon after being activated will experience a transmittant percentage increase at wavenumber $3434 \mathrm{~cm}^{-1}$, which implies that there is an $\mathrm{O}-\mathrm{H}$ stretching vibration which may be caused by the addition of alkaline functional group on the carbon pores. This matches with the research undertaken by Lee and Park 2012b, which reported the addition of alkaline functional group after being activated without oxidation on zeolite template carbon. At the same time, a shift in wavenumber also occurred, from $1575 \mathrm{~cm}^{-1}$ and $1193 \mathrm{~cm}^{-1}$ to 1617 $\mathrm{cm}^{-1}$ and $1009 \mathrm{~cm}^{-1}$. The shift in wavenumber also proved that carbon activation has been successfully undertaken in this research, which matches the research undertaken by Cuhadaroglu and Uygun 2008. Figures 2c and $2 \mathrm{~d}$ also show a sharper peak on wavenumber $2906 \mathrm{~cm}^{-1}$, which suggest that there was a bending vibration on the $\mathrm{C}-\mathrm{H}$ and at $1391 \mathrm{~cm}^{-1}$. According to Cuhadaroglu and Uygun, 2008, the presence of stronger adsorption bands at wavenumbers of approximately $2900 \mathrm{~cm}^{-1}$ and $1300 \mathrm{~cm}^{-1}$ were caused by activating the MOF-5 templated carbon. Such finding strengthens the fact that MOF-5 templated carbon has been successfully activated using $\mathrm{KOH}$. A sharper peak at $442 \mathrm{~cm}^{-1}$ can also still be seen, which suggests that there were still some concentrations of $\mathrm{ZnO}$ being left behind after MOF-5 templated carbon has been activated.

\section{Surface Morphology}

SEM images of MOF-5 templated carbons are presented in Figure 3. The C-MOF-5-550 has a cubical morphology as the template used, which means that the carbon produced has a template similar as the MOF-5 (Figure 3a).

On the other hand, the surface texture generated was more uneven and had more layers, due to the possibility of the presence of $\mathrm{ZnO}$ and carbon phases. This also implies that at a carbonation temperature of $550{ }^{\circ} \mathrm{C}$, a MOF-5 templated porous carbon has been formed, with the existence of $\mathrm{ZnO}$, as with the research of Liu et al., 2010. When carbonation temperature was increased to $900{ }^{\circ} \mathrm{C}$ (Figure 3b), C-MOF-5-900 has circular and cubical morphologies. This may be due to the $\mathrm{ZnO}$ yielded by the decomposition of MOF-5 that has not evaporated perfectly (Yang et al., 2012). The leftover $\mathrm{ZnO}$ was then separated into a circular morphology.

Figure 3c shows that AC-MOF-5-550 has a surface morphology in the shape of a stem, which was different to the morphology prior to activation (cubical) with smaller size. At the same time, AC-MOF-5-900 (Figure 3d) has cubical surface morphology as before it was being activated, only with smaller size. This may be due to the unseparated $\mathrm{ZnO}$ from AC-MOF-5-550, hence resulting in imperfect activation results. According to (Lee and Park, 2012b), the existence of acidic or alkaline functional groups on zeolite template carbon due to the activation without oxidation process caused some defects to the carbon morphology. This in turn caused the morphology on the carbon surface to differ compared to before it was activated. On AC-MOF-5-900, the $\mathrm{ZnO}$ has been separated from the carbon, resulting in a more complete activation. The smaller AC-MOF-5-900 could be a possibility which shows that a $\mathrm{KOH}$ intercalation had occurred on MOF-5 templated porous carbon, which formed an active carbon. 


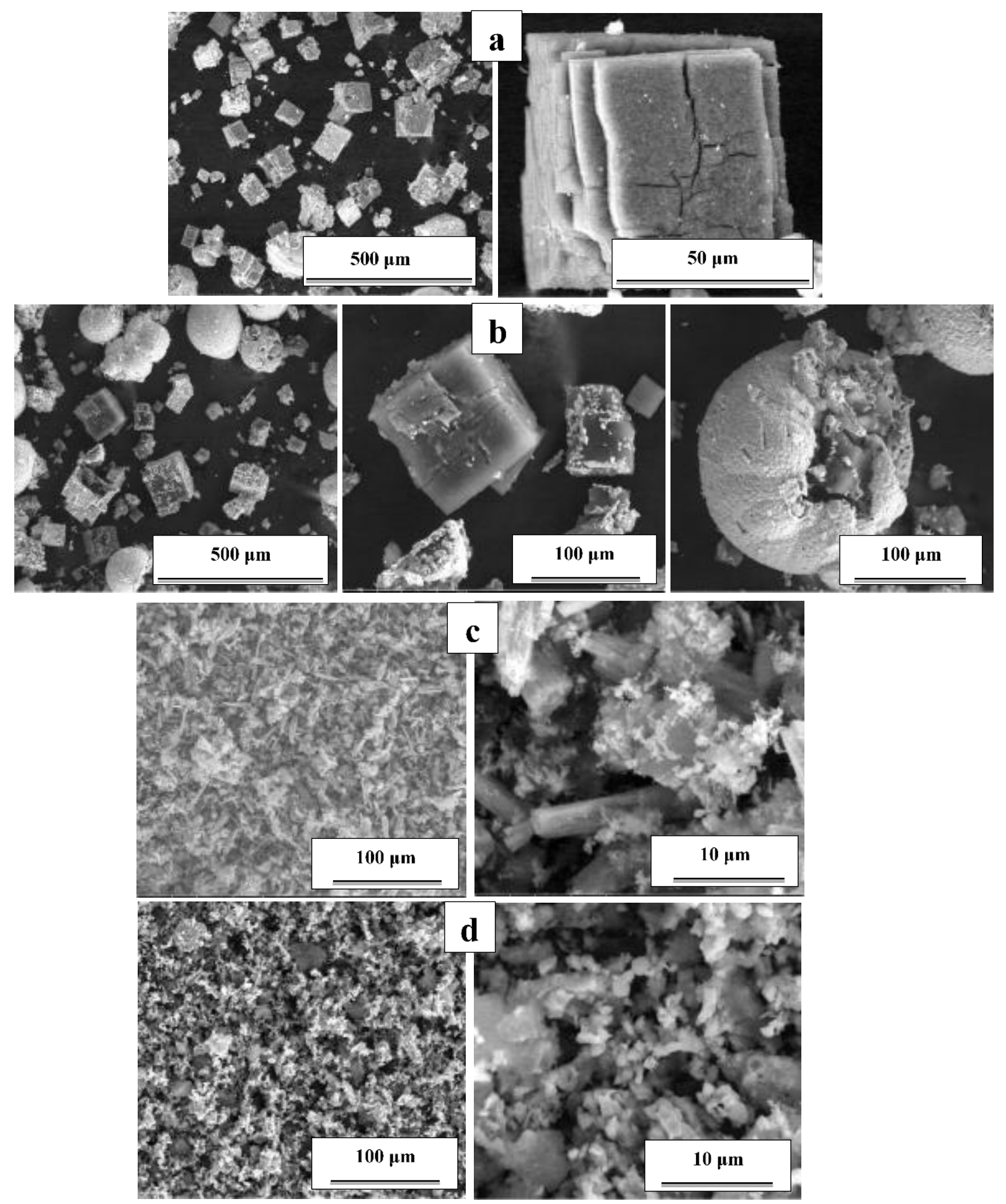

Figure 3. SEM images of MOF-5 templated carbons, (a) C-MOF-5-550, (b) C-MOF-5-900, (c) AC-MOF-5-550 and (d) AC-MOF-5-900.

\section{Element Composition Analysis}

The element compositions, which comprise the MOF-5 templated carbon before and after being activated, are both shown in Figure 4 and Table 1. Based on Figure 4, it is seen that the MOF-5 templated carbon has the same elements before and after it is activated, which is carbon $(\mathrm{C})$, oxygen $(\mathrm{O})$, and zinc $(\mathrm{Zn})$. This matches with the diffractogram pattern which stated that the carbon produced contained a $\mathrm{ZnO}$ phase. Table 1 shows that C-MOF-5-550 has a higher carbon composition (44.65 $\mathrm{wt} \%$ ) 
compared to the carbon composition in the MOF-5 template (42.28 wt \%). At the same time, C-MOF-5-550 also has a lower zinc composition (23.87 wt\%) compared to the zinc composition in the MOF-5 template (30.15 wt\%). This shows that MOF-5 solids have been carbonized in order to form a porous templated carbon, hence reducing the zinc composition. On the other ihand, the zinc element composition can be said
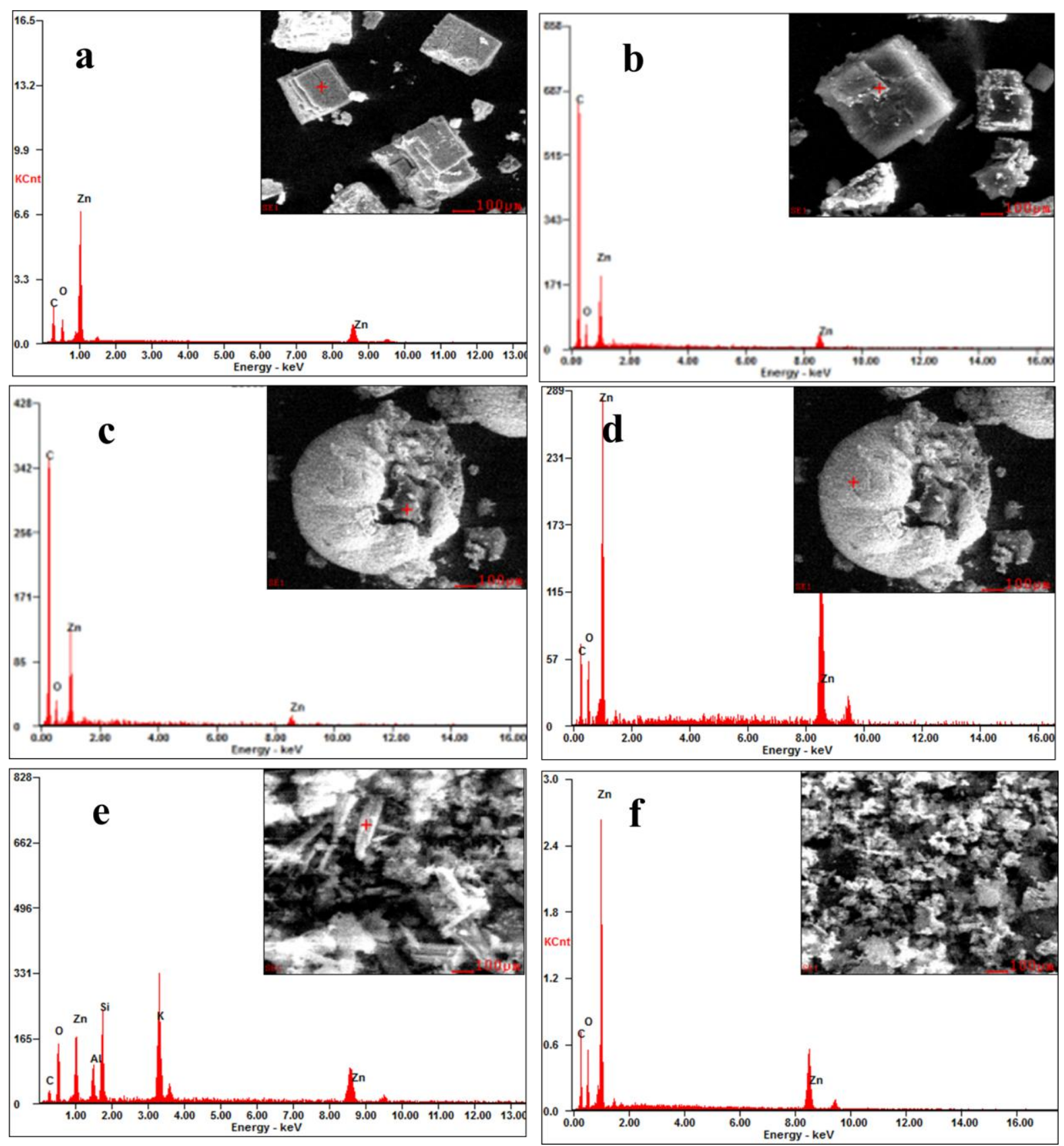

Figure 4. EDX spectra of the MOF-5 templated carbon, (a) C-MOF-5-550, (b-d) C-MOF-5-900, (e) AC-MOF-5-550 and (f) AC-MOF-5-900. as relatively high due to the relatively low carbonation temperature used $\left(550^{\circ} \mathrm{C}\right)$, leading to $\mathrm{ZnO}$ being produced in addition to carbon material as shown by (Jiang et al., 2011). This coincides with the diffractogram pattern as well as the research undertaken by (Liu et al., 2010), which stated that at carbonation temperature of $550^{\circ} \mathrm{C}$, a $\mathrm{ZnO}$ is formed. 
Table 1. Element composition of the MOF templated carbon

\begin{tabular}{lccc}
\hline \multicolumn{1}{c}{ Sample } & Composisiton C (wt\%) & Composisiton O (wt\%) & Composisiton Zn (wt\%) \\
\hline C-MOF-5-550 (a) & 44.65 & 31.47 & 23.87 \\
C-MOF-5-900 cubic (b) & 76.70 & 16.36 & 6.94 \\
C-MOF-5-900 circle (c) & 75.80 & 19.18 & 5.03 \\
C-MOF-5-900 circle (d) & 34.66 & 19.13 & 46.21 \\
AC-MOF-5-550 (e) & 33.50 & 31.01 & 35.49 \\
AC-MOF-5-900 (f) & 56.31 & 26.90 & 16.74 \\
\hline
\end{tabular}

\section{Surface Area and Pore Volume Analysis}

The nitrogen adsorption desorption isotherm displayed in Figure 5 implies that the original MOF-5, MOF-5 templated carbon, as well as MOF-5 templated active carbon started to adsorb nitrogen at low pressure $\left(\mathrm{P} / \mathrm{P}_{0}<0.1\right)$, which further implied a presence of micropores. Nitrogen adsorption would increase due to the increasing relative pressure, which caused by the existence of monolayer or multilayer adsorption from nitrogen molecules on the mesopores or micropores (Lee and Park, 2012b). When the relative pressure was being decreased, a nitrogen gas desorption took place. A hysteresis loop also occurred at a higher relative pressure $\left(\mathrm{P} / \mathrm{P}_{0}\right.$ 0.4-1), which suggests the existence of mesoporous structure. Figures $5 \mathrm{~b}$ and $5 \mathrm{c}$ displayed that hysteresis loop occurred at $\mathrm{P} / \mathrm{P}_{0}$ 0.4-1, whilst after being activated, hysteresis loop occurred at $\mathrm{P} / \mathrm{P}_{0} 0.2-1$, as presented in Figures $5 \mathrm{~d}$ and $5 \mathrm{e}$. This results indicated that either prior or after activation, a mesoporous solids structure was formed (Hu et al., 2010; Liu et al., 2010). The forming of mesoporous was due to the possibility of incomplete precursor filtration process from the micropores in further addition to high carbonation temperature (Lee and Park, 2012b).

The higher the carbonation temperature, the narrower the hysteresis loop, which signified the decreasing proportion or amount of mesopores (Sevilla et al., 2010). This might be caused by the $\mathrm{ZnO}$ which had been separated and covered the MOF-5 templated carbon pores, as displayed in the SEM in Figure 3b. On the contrary, activation of the MOF-5 templated carbon with $\mathrm{KOH}$ (Figures $5 \mathrm{~d}$ and $5 \mathrm{e}$ ) caused the hysterersis loop to be widen which further suggested that there was an increasing proportion or amount of mesopores. This might be induced to the presence of new pores being formed due to the activation process, as suggested by Lee and Park., 2012b. The surface area and pore volume data of the MOF-5 as well as MOF-5 templated carbon before and after being activated are shown in Table 2 .

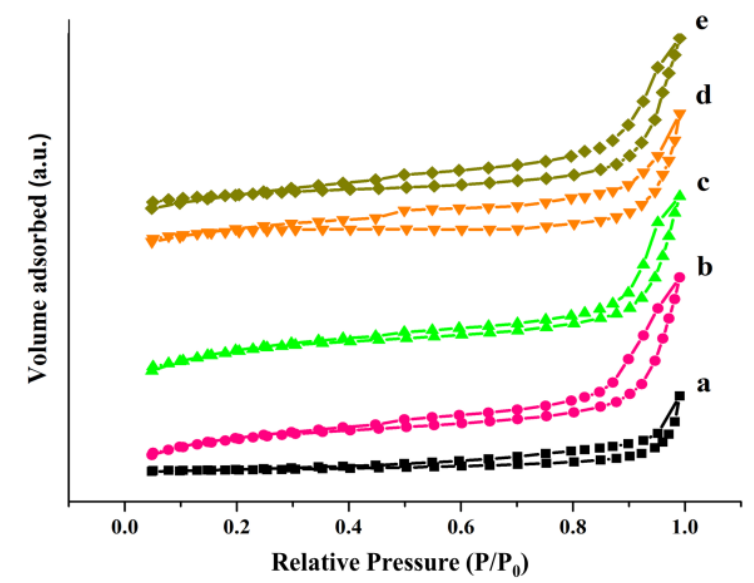

Figure 5. Nitrogen adsoption desorption isotherms of the MOF-5 templated carbon, (a) MOF-5, (b) C-MOF-5-550, (c) C-MOF-5-900, AC-MOF-5-550 and (e) AC-MOF-5-900.

Table 2. The surface area and pore volume data of the MOF-5.

\begin{tabular}{lccc}
\hline Sample & $\begin{array}{c}\text { Surface } \\
\text { Area } \\
\left(\mathbf{m}^{\mathbf{2}} / \mathbf{g}\right)\end{array}$ & $\begin{array}{c}\text { Pore } \\
\text { Diameter } \\
(\mathbf{n m})\end{array}$ & $\begin{array}{c}\text { Pore } \\
\text { Volume } \\
\left(\mathbf{c m}^{\mathbf{3}} \mathbf{g}\right)\end{array}$ \\
\hline MOF-5 & 7.58 & 1.31 & 0.047 \\
C-MOF-5-550 & 89.56 & 3.08 & 0.138 \\
C-MOF-5-900 & 93.95 & 2.87 & 0.135 \\
AC-MOF-5-550 & 74.54 & 2.87 & 0.107 \\
AC-MOF-5-900 & 73.14 & 3.51 & 0.129 \\
\hline
\end{tabular}

Table 2 shows that by carbonating the MOF-5 solids into MOF-5 templated carbon could increase the surface area and the pore volume (Yang et al., 2012). At a high carbonation temperature $\left(900{ }^{\circ} \mathrm{C}\right)$, the surface area produced also increased (Liu et al., 2010). However, Yang et al., (2012) have shown otherwise, where the surface area produced was smaller due to the presence of $\mathrm{ZnO}$ on the carbon which could obstruct the carbon pores (Yang et al., 2012). As a result, the process of nitrogen 
gas adsorption was also obstructed, resulting in a smaller measured surface area of the carbon itself. The larger the percentage of zinc, the smaller the measured surface area of the carbon, which matched with the results obtained from SEM-EDX.

Table 2 also shows that by activating $\mathrm{KOH}$ on MOF-5 templated carbon not only decreased the surface area, but also the pore volume. A similar phenomenon was also reported by. $\mathrm{Hu}$ et al., 2010, which stated that activating $\mathrm{KOH}$ on MOF-5 templated carbon by adding phenol resin precursor could cause the surface area and pore volume to decrease to the new pores being formed. According to Lee and Park, 2012b, activating zeolite template carbon with either acid or alkali without oxidation could decrease the surface area and the volume of the pores due to the presence of the functional groups from the acid or alkali, which can be found the walls of the pores, causing damage to the carbon morphology. The decrease in the surface area could also suggest that the functional groups of the acid or alkali entered the surface of the zeolite-templated porous carbon, which was expected to be able to increase the hydrogen storage capacity. Besides the presence of alkaline functional groups, the decrease in the surface area could also be caused by the presence of $\mathrm{ZnO}$ in the carbon before being activated, which could obstruct the activation process itself, hence causing an imperfect activation process.

\section{Pore Size Distribution Analysis}

The pore size distribution presented in Figure 6 shows that after MOF- 5 was carbonated into a MOF-5 templated carbon, it experienced an increase in the amount of micropores and mesopores (3-4 nm) (Lee and Park., 2012b).

The increase in the amount of micropores was caused by the forming of micropores during the process of FA carbonation in the MOF-5 template, which corresponds to the research conducted by Sculley et al. (Sculley et al., 2011). The higher the carbonation temperature (Figures $6 \mathrm{~b}$ and $6 \mathrm{c}$ ), the smaller the mesopore structure, which came as a result due to the high carbonation temperature $\left(900{ }^{\circ} \mathrm{C}\right)$ formed from the unevaporated $\mathrm{ZnO}$ which has been separated from the carbon and obstructing the carbon pores. Moreover, by activating $\mathrm{KOH}$ on the MOF-5 templated carbon could also improve the mesopore structure (Figures $6 \mathrm{~d}$ and $6 \mathrm{e})$, as presented in the research undertaken by
Hu et al., 2010. This further implied that there was a presence of new pores being formed during the process of activation, in further addition where by adding a dehydration substance ( $\mathrm{KOH}$ activator) could uniform the pore size (Yang et al., 2016).

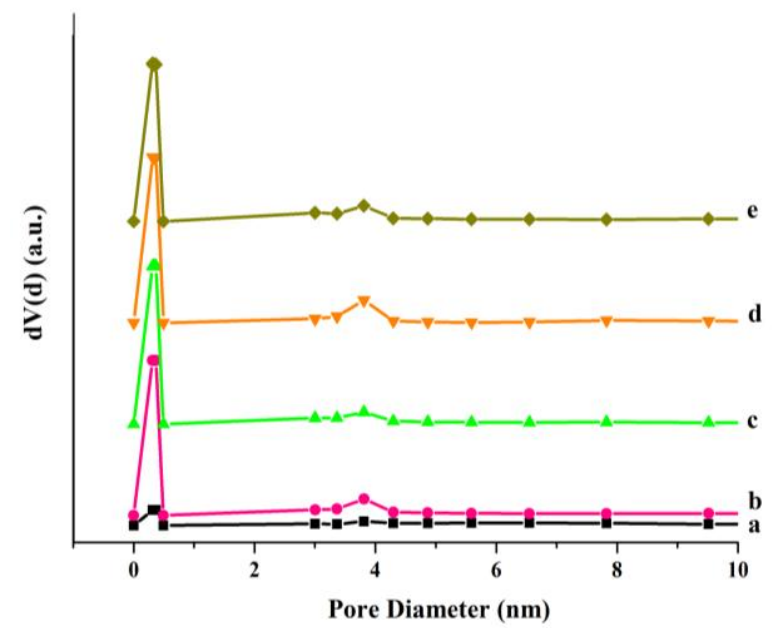

Figure 6. Pore size distribution of MOF-5 templated Carbon,(a) MOF-5, (b) C-MOF-5-550, C-MOF-5-900, (d) AC-MOF-5-550 and AC-MOF-5-900.

\section{Hydrogen Storage}

The hydrogen adsorption test has been conducted using gravimetric method, which is a method of measuring weight using a scale to determine the storage capacity of a material. The adsorption process was performed on the sample that has been degassed, by streaming $\mathrm{H}_{2}$ gas at room temperature and atmospheric pressure with gas flow of $20 \mathrm{~mL} /$ minute. The change in mass being observed in the analytic scale was noted every minute up until 50 minutes. The mass difference before and after the sample was flown with $\mathrm{H}_{2}$ gas was noted and calculated, and hence the difference produced was the percentage amount of $\mathrm{H}_{2}$ gas being adsorbed into the sample. The hydrogen adsorption results are shown in Table 3.

Based on Table 3, it is indicated that both the carbonation and activation processes could increase the hydrogen adsorption. At the beginning, the MOF-5 solids had hydrogen adsorption of $0.48 \%$. However, after being turned into a carbon template, C-MOF-5-550 had hydrogen adsorption of $0.76 \%$, whilst C-MOF-5-900 of $0.96 \%$. This suggests that the higher the carbon carbonation temperature, the higher the hydrogen adsorption. There is a possibility that this is due to the increase of surface area and pore volume of the carbon. 
According to Song et al., 2013 the hydrogen storage capacity was directly proportional to the surface area and pore volume, since hydrogen adsorption that occurred in porous materials was physically adsorbed (Song et al., 2013). The mechanism occurred was hydrogen filled up the pores followed by the layer formation. The increase of hydrogen adsorption on MOF-5 templated carbon could also be caused by the presence of $\mathrm{Zn}$ and $\mathrm{ZnO}$ in the carbon. According to Hirscher et al. the bonds between the hydrogen compounds with the transitional metals (such as $\mathrm{Zn}$ ) caused the bonds between the hydrogen atoms $(\mathrm{H}-\mathrm{H})$ to become unstable (Hirscher et al., 2010; Chen et al., 2012). This in turn caused the $\mathrm{H}-\mathrm{H}$ bond to break up easily, the $\mathrm{H}$ atoms to enter the carbon pores, which led to the increase in the hydrogen storage capacity of the carbon.

Table 3. Results of hydrogen storage adsorption

\begin{tabular}{lc}
\hline Sample & Hydrogen Adsorption (\%) \\
\hline MOF-5 & 0.48 \\
C-MOF-5-550 & 0.76 \\
C-MOF-5-900 & 0.96 \\
AC-MOF-5-550 & 1.18 \\
AC-MOF-5-900 & 1.24 \\
\hline
\end{tabular}

Table 3 also shows that activating $\mathrm{KOH}$ on MOF-5 templated carbon could increase the hydrogen adsorption. Although both AC-MOF-5-550 and AC-MOF-5-900 have smaller surface area and pore volumes compared to both C-MOF-5-550 and C-MOF-5-900. However, active carbon had a higher hydrogen adsorption due to the presence of alkaline groups in the active carbon itself. On the contrary, the presence of both acidic and alkaline groups could attract hydrogen molecules into the pores of active carbon, hence increasing the hydrogen storage capacity in the carbon. Furthermore, AC-MOF-5-900 has higher hydrogen adsorption compared to AC-MOF-5-550, causing AC-MOF-5-900 to have a bigger pore volume compared to AC-MOF-5-550, enabling AC-MOF-5-900 to have more hydrogen filling layers, which what caused AC-MOF-5-900 to have a higher hydrogen adsorption.

When compared to the research conducted by Yang et al., (2012) where it was shown that hydrogen adsorption could reach $3 \%$, the results from our research showed a smaller hydrogen adsorption (Yang et al., 2012). This was due to the measurements that were performed at room temperature, whereas the results from the research conducted by Yang et al., 2012 was performed at $77 \mathrm{~K}$. According to Hirscher et al., 2010, if a high temperature used at low pressure, the hydrogen gas would have difficulty to be adsorbed into the adsorbent pores due to the faster movements of hydrogen, making it more difficult to be adsorbed into the adsorbent pores.

\section{CONCLUSION}

The MOF- 5 has been successfully used as a carbon nanopore reservoir with or without activation using $\mathrm{KOH}$. The analysis results indicated that the treatment of carbonation temperature and activation could affect the surface morphology, pore size, surface area, and pore volume of the material. The gravimetric hydrogen adsorption test showed that the carbon material with the MOF-5 template and after activation with $\mathrm{KOH}$ could increase the hydrogen storage capacity of AC-MOF 5-900 at a room temperature and an atmospheric pressure by $1.24 \%$.

\section{ACKNOWLEDGMENT}

Authors would like to acknowledge funding from Ministry of Education and Culture Republic of Indonesia under Postgraduate Grant 2019, Institut Teknologi Sepuluh Nopember Surabaya and Department of Chemistry, Faculty of Science and Data Analytics ITS for all facilities supporting this works.

\section{REFERENCES}

Almasoudi A, Mokaya R. 2012. Preparation and hydrogen storage capacity of templated and activated carbons nanocast from commercially available zeolitic imidazolate framework. Journal of Materials Chemistry. 22(1): 146-152. https://doi.org/10.1039/c1jm13314d.

Ata-ur-Rehman, Tirmizi SA, Badshah A, Ammad HM, Jawad M, Abbas SM, Rana UA, Khan SUD. 2018. Synthesis of highly stable MOF-5@MWCNTs nanocomposite with improved hydrophobic properties. Arabian Journal of Chemistry. 11(1): 26-33. https://doi.org/10.1016/j.arabjc.2017.01.012

Chen EY, Liu YC, Zhou M, Zhang L, Wang Q. 2012. Effects of structure on hydrogen adsorption in zeolitic imidazolate frameworks. 
Chemical Engineering Science. 71: 178184.

https://doi.org/10.1016/j.ces.2011.12.003

Cuhadaroglu D, Uygun OA. 2008. Production and characterization of activated carbon from a bituminous coal by chemical activation. African Journal of Biotechnology. 7(20): 3706-3713.

https://doi.org/10.5897/AJB08.588

Ediati R, Mukminin A, Widiastuti N. 2017. Impregnation nickel on mesoporous ZSM-5 templated carbons as a candidate material for hydrogen storage. Indonesian Journal of Chemistry. 17(1): 30-36.

Greer HF, Liu Y, Greenaway A, Wright PA, Zhou W. 2016. Synthesis and formation mechanism of textured MOF-5, crystal growth and design. 16(4): 2104-2111. https://doi.org/10.1021/acs.cgd.5b01785

Hirscher M, Panella B, Schmitz B. 2010. Metal-organic frameworks for hydrogen storage. Microporous and Mesoporous Materials. $\quad$ 129(3): 335-339. https://doi.org/10.1016/j.micromeso.2009.0 6.005

Hou XX, Sulic M, Ortmann JP, Cai M, Chakraborty A. 2016. Experimental and numerical investigation of the cryogenic hydrogen storage processes over MOF-5. International Journal of Hydrogen Energy. 41(6): $\quad$ 4026-4038. https://doi.org/10.1016/j.ijhydene.2015.12.1 87

Hu J, Wang H, Gao Q, Guo H. 2010. Porous carbons prepared by using metal-organic framework as the precursor for supercapacitors. Carbon. 48(12): 3599-3606. https://doi.org/10.1016/j.carbon.2010.06.00 8

Hu YH, Zhang L. 2010. Hydrogen storage in metal-organic frameworks. Advanced Materials. $\quad 22(20): \quad 117-130$. https://doi.org/10.1002/adma.200902096

Jiang HL, Liu B, Lan YQ, Kuratani K, Akita T, Shioyama H, Zong F, Xu Q. 2011. From metal-organic framework to nanoporous carbon: toward a very high surface area and hydrogen uptake. Journal of the American Chemical Society. 133(31): 11854-11857. https://doi.org/10.1021/ja203184k

Juan-Juan J, Marco-Lozar JP, Suárez-García F,
Cazorla-Amorós D, Linares-Solano A. 2010. A comparison of hydrogen storage in activated carbons and a metal-organic framework (MOF-5). Carbon. 48(10): 2906-2909. https://doi.org/10.1016/j.carbon.2010.04.02 5

Khan IA, Badshah A, Khan I, Zhao D, Nadeem MA. 2017. Soft-template carbonization approach of MOF-5 to mesoporous carbon nanospheres as excellent electrode materials for supercapacitor. Microporous and Mesoporous Materials. 253: 169-176. https://doi.org/10.1016/j.micromeso.2017.0 6.049

Lee SY, Park SJ. 2012a. Influence of the pore size in multi-walled carbon nanotubes on the hydrogen storage behaviors. Journal of Solid State Chemistry. 194: 307-312. https://doi.org/10.1016/j.jssc.2012.05.027

Lee SY, Park SJ. 2012b. Synthesis of zeolite-casted microporous carbons and their hydrogen storage capacity. Journal of Colloid and Interface Science. 384(1): 116-120. https://doi.org/10.1016/j.jcis.2012.06.058

Lestari WW, Wibowo AH, Astuti S, Irwinsyah, Pamungkas AZ, Krisnandi YK. 2018. Fabrication of hybrid coating material of polypropylene itaconate containing MOF-5 for $\mathrm{CO}_{2}$ capture. Progress in Organic Coatings. 115(November 2017): 49-55. https://doi.org/10.1016/j.porgcoat.2017.11.0 06

Li W, Zhang Y, Li Q, Zhang G. 2015. Metal-organic framework composite membranes: Synthesis and separation applications. Chemical Engineering Science. 135: 232257.

https://doi.org/10.1016/j.ces.2015.04.011

Liu B, Shioyama H, Jiang H, Zhang X, Xu Q. 2010. Metal-organic framework (MOF) as a template for syntheses of nanoporous carbons as electrode materials for supercapacitor. Carbon. 48(2), 456-463. https://doi.org/10.1016/j.carbon.2009.09.06 1

Liu XW, Sun TJ, Hu JL, Wang SD. 2016. Composites of metal-organic frameworks and carbon-based materials: Preparations, functionalities and applications. Journal of Materials Chemistry A. 4(10): 3584-3616. https://doi.org/10.1039/c5ta09924b 
Ma X, Li L, Chen R, Wang C, Li H, Wang S. 2018. Heteroatom-doped nanoporous carbon derived from MOF-5 for $\mathrm{CO}_{2}$ capture. Applied Surface Science. 435(2010): 494 502.

https://doi.org/10.1016/j.apsusc.2017.11.06 9

Ming Y, Purewal J, Yang J, Xu C, Veenstra M, Gaab M, Müller U, Siegel DJ. 2016. Stability of MOF-5 in a hydrogen gas environment containing fueling station impurities. International Journal of Hydrogen Energy. 41(22): $\quad$ 9374-9382. https://doi.org/10.1016/j.ijhydene.2016.03.1 55

Mulyati TA, Ediati R, Rosyidah A. 2015. Influence of solvothermal temperatures and times on crystallinity and morphology of MOF-5. Indonesian Journal of Chemistry. 15(2): 101-107. https://doi.org/10.22146/ijc.21202

Sculley J, Yuan D, Zhou HC. 2011. The current status of hydrogen storage in metal-organic frameworks-updated. Energy and Environmental Science. 4(8): 2721-2735. https://doi.org/10.1039/c1ee01240a

Segakweng T, Musyoka NM, Ren J, Crouse P, Langmi HW. 2016. Comparison of MOF-5and $\mathrm{Cr}-\mathrm{MOF}$-derived carbons for hydrogen storage application. Research on Chemical Intermediates. 42(5): 4951-4961. https://doi.org/10.1007/s11164-015-2338-1

Sevilla M, Fuertes AB, Mokaya R. 2011. Preparation and hydrogen storage capacity of highly porous activated carbon materials derived from polythiophene. International Journal of Hydrogen Energy. 36(24): 15658-15663. https://doi.org/10.1016/j.ijhydene.2011.09.0 32

Sevilla, Marta, Alam N, Mokaya R. 2010. Enhancement of hydrogen storage capacity of zeolite-templated carbons by chemical activation. Journal of Physical Chemistry $C$. 114(25): 11314-11319.

https://doi.org/10.1021/jp102464e

Song J, Guo Q, Zhong Y, Gao X, Feng Z, Fan Z, Shi J, Liu L. 2013. Abstracts of new carbon materials 2012(1). Carbon. 50(8): 31173118.

https://doi.org/10.1016/j.carbon.2012.02.07 0

Srinivas G, Krungleviciute V, Guo ZX, Yildirim T. 2014. Exceptional $\mathrm{CO}_{2}$ capture in a hierarchically porous carbon with simultaneous high surface area and pore volume. Energy and Environmental Science. 7(1): 335-342. https://doi.org/10.1039/c3ee42918k

Yaghi OM, O’Keeffe M, Eddaoudi M, Li H. 1999. Design and synthesis of an exceptionally stable and highly. Letters to Nature, 402(November): 276-279.

Yang M, Guo L, Hu G, Hu X, Chen J, Shen S, Dai W, Fan M. 2016. Adsorption of $\mathrm{CO}_{2}$ by petroleum coke nitrogen-doped porous carbons synthesized by combining ammoxidation with $\mathrm{KOH}$ activation. Industrial and Engineering Chemistry Research. 55(3): 757-765. https://doi.org/10.1021/acs.iecr.5b04038

Yang SJ, Kim T, Im JH, Kim YS, Lee K, Jung H, Park CR. 2012. MOF-derived hierarchically porous carbon with exceptional porosity and hydrogen storage capacity. Chemistry of Materials. $\quad 24:$ 464-470. https://doi.org/10.1021/cm202554j

Yap MH, Fow KL, Chen GZ. 2017. Synthesis and applications of MOF-derived porous nanostructures. Green Energy \& Environment. 2(3): 218-245. https://doi.org/10.1016/j.gee.2017.05.003 